\title{
Reproductive Toxicity of the Water Accommodated Fraction (WAF) of Crude Oil in the Polychaetes Arenicola marina (L.) and Nereis virens (Sars).
}

\section{Ceri Lewis, Chris Pook \& Tamara Galloway}

School of Biosciences, Hatherley Laboratories, University of Exeter, Prince of Wales Road, Exeter, UK, EX4 4PS. Tel: +44 (0)1392 264672, fax 0(44) 1392263700 Corresponding Author E-mail: c.n.lewis@exeter.ac.uk

\begin{abstract}
Accidental pollution incidents are common in the marine environment and are often caused by oil related activities. Here the potential of such an incident to disrupt reproduction in two polychaete species is investigated, using an environmentally relevant preparation of weathered Forties crude oil, i.e. the water accommodated fraction (WAF). Oocytes were collected and exposed to three concentrations of WAF for 1 hour prior to the addition of sperm, so that fertilization took place under exposure conditions. Fertilization success was significantly reduced in both species by an exposure to WAF concentrations equivalent to $0.38 \mathrm{mg} \mathrm{L}^{-1} \mathrm{PAHs}$, to just $26.8 \%$ in Arenicola marina compared to $76 \%$ in Nereis virens. The effects of WAF exposure on fertilization were greatly enhanced at lower sperm concentrations in $\underline{N}$. virens, with a complete lack of fertilization reactions observed at sperm concentrations of $10^{3}$ sperm per $\mathrm{ml}$. We therefore suggest a mechanism of toxicity related to sperm swimming behaviour, resulting in reduced sperm: egg collision rates. WAF was found to reduce post-fertilization development rates and have teratogenic effects on early embryonic stages in both species. These results illustrate how the presence of crude oil in its soluble form in seawater at the time of a spawning event for either
\end{abstract}


Arenicola marina or Nereis virens could impact on fertilization success with

implications for the fertilization ecology of these free spawning marine invertebrates.

Keywords: fertilization; embryo; development; sperm; polyaromatic hydrocarbons

\section{Introduction}

Crude oil enters the marine environment from a number of natural and anthropogenic sources, though both chronic pollution and accidental spills. The toxicological effects of acute exposures to oil pollution and polycyclic aromatic hydrocarbons (PAHs) on the health of aquatic organisms have received much attention (Bonsdorff et al., 1990; Bejarano et al., 2006), however the longer-term implications and population level effects of such exposures are still poorly understood. Crude oil is highly unstable in the marine environment, quickly loosing the volatile fractions through weathering (Payne et al., 1992, Smith et al., 2006) and becoming both photo-and biodegraded. Prolonged turbulent mixing by wind and currents results in the release of a water accommodated (or soluble) fraction (WAF) mainly comprised of naphthalene (Rossi

\& Anderson, 1976; Wolfe et al., 1998; Barron et al., 1999; Pollino \& Holdway, 2002). This water-soluble fraction has been shown to be highly toxic to the embryos of fish (e.g. Middaugh and Whiting, 1995; Pollino \& Holdway, 2002; Couillard et al., 2005); starfish (Davis et al., 1981) and crustaceans (e.g. Cucci \& Epifanio, 1979; Johns \& Pechenik, 1980) from pristine environments.

Polychaetes tend to form the dominant sediment dwelling fauna of most mud flats, estuaries and sheltered sandy shores, and so are often found in areas of chronic oil pollution or areas affected by acute spills. There is evidence to suggest certain Polychaete species are particularly tolerant to PAHs (De Boeck and Kirsch-Volders, 
1998; Lewis \& Galloway, 2008). Nereis virens in particular is often found in sediments affected by chronic PAH contamination (Lewis \& Galloway, 2008) and experimental field studies have shown some Polychaetes are able to recruit soft sediments heavily contaminated with hydrocarbons in large numbers (Stark et al., 2003). Little is currently known however, regarding any impacts of oil pollution on their fertilization or developmental biology.

WAF is the oil component most likely to have any effect on reproduction in freespawning sediment-dwelling marine invertebrates during any spill incident as oocytes and sperm, and subsequently developing embryos and larval stages are released freely in the water column. The two polychaetes used in this investigation differ slightly from a typical broadcast spawning strategy in that their oocytes are spawned in the female burrow (in the case of Arenicola marina) or in shallow pools at low tide (Nereis virens), hence the exposure routes for oocytes will differ slightly from a true broadcast spawning species and are likely to be highly complex. Sperm are released freely into the incoming tide by both species, which are then drawn into the female

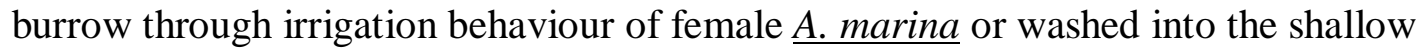
pools containing the oocytes of $N$. virens, enabling fertilization to take place. Exposure to spilled oil contamination may, therefore, also occur via direct contact to stranded oil bound to intertidal sediments, however this would be complex and difficult to mimic experimentally hence for the purposes of this investigation we aim to focus on the soluble WAF components of the oil in which the sperm would be present and in which the fertilization reaction would therefore occur.

Invertebrate oocytes contain a significant amount of vitellin (yolk) which is a heavy (420,000 daltons) lipoglycoprotein (Fischer \& Schmitz, 1981), and therefore are 
highly likely to readily sequester hydrophobic polycyclic aromatic hydrocarbons (PAHs). Most studies looking at PAH affects on sperm (mainly human and vertebrate studies) relate to metabolite induced DNA damage (e.g. Gaspari et al., 2003; Hsu et al., 2006), however naphthalene and the other smaller water soluble PAHs found in WAF are not widely considered to have genotoxic properties (reviewed by Schreiner, 2003). There have been a number of studies describing reduced fertilization rates in a number of broadcast spawning coral species exposed to petroleum based extracts (e.g. Negri \& Heyward, 2000; Harrison, 1994), however the precise mechanisms by which WAF disrupts external fertilization have not been widely studied in marine invertebrates, with the majority of studies focusing on embryo and larval development.

The majority of larger marine invertebrate species, including Arenicola marina and Nereis virens, reproduce by releasing their eggs and/or sperm into the water column so that fertilization takes place externally. These spawning episodes can be highly seasonal, with offspring production often confined to just one-two weeks of the year (e.g. Caspers et al., 1984; Goerke, 1984; Olive et al., 2000; Watson et al., 2000; Guest et al., 2005). The potential risks of such a highly confined spawning period being disrupted were illustrated in November 1981, when mass spawning on the Great Barrier Reef coincided with heavy rainfall. Propagules on the surface were killed, thereby destroying the whole reproductive effort of those corals for that year (Harrison et al., 1984). Similar catastrophic reproductive failure was described for Mytilus edulis when spawning coincided with a brown tide in Rhode Island (Tracey, 1988). Fertilization and early post-fertilization development are widely considered to be the most sensitive life history stages to disruption through disturbances such as temperature change or the presence of environmental pollutants (Andronikov, 1975; 
His et al., 1999). Successful fertilization is a critical step in the life history of a species, but particularly so for broadcast and free spawning marine invertebrate (Pennington, 1985), where sperm is often limiting and fertilization success is rarely $100 \%$ even under optimal conditions of temperature and water quality (Levitan, 1995). Population dynamics in many free spawning marine invertebrates is thought to be sperm limited (e.g. Denny and Shibata, 1989; Levitan 1995; Yund, 2000), particularly where population density is low. Actual field data on sperm limitation and fertilization dynamics for free spawning marine invertebrates are sparse but a few studies have shown a proportion of oocytes may remain unfertilized (Levitan \& Petersen, 1995; Williams 1998; Bode \& Marshall, 2007). Any additional effect of a pollutant on reduced fertilization success may therefore have significant implications for population dynamics.

In this study the effects of an environmentally relevant preparation of weathered forties crude oil, i.e. the water accommodated fraction (WAF) on reproduction and development in two polychaetes are investigated. The lugworm, Arenicola marina and the king ragworm, Nereis virens are ecologically important benthic polychaetes, with highly seasonal epidemic spawning (Olive et al., 2000; Watson et al., 2000). Both of these species are found in areas regularly at risk from oil related pollution events, hence it is essential that we understand the risks to the population resulting from gamete and larval exposure. Spawning episodes for $\underline{\text { A. marina }}$ are typically only 3-4 days long (Watson et al., 2000), which may exacerbate considerably the potential effects on a population's reproductive success. Less is known for $\underline{N \text {. virens }}$ but some parts of a population also seem to spawn over very short periods of a few days. Effects of WAF generated from weathered Forties crude oil on fertilization success and early post fertilization for these two species are therefore determined via a series 
of laboratory exposures and the developmental stability of resulting larvae is determined using a fluctuating asymmetry bioassay.

\section{Materials and Methods}

\subsection{Collection and maintenance of animals}

Mature Arenicola marina specimens were collected from the beach at Mothercombe estuary, South Devon (50¹8'41" N, 356'45" W), during October-November 2006. This site is relatively free from contamination according to Environment Agency (2007) data. Individual animals were collected according to the methods of Lewis et al. (2002) and returned to the laboratory where they were checked for maturity, then stored at $12^{\circ} \mathrm{C}$ in individual containers in filtered $(0.2 \mu \mathrm{m})$ seawater $(\mathrm{FSW})$. Animals were maintained in 10 litre glass aquarium tanks in well aerated FSW for two days post digging to allow their gut contents to be voided.

Adult Nereis virens were collected from the muddy shore at Torpoint, in the Tamar estuary, Cornwall (50²2'14"N, $\left.4^{\circ} 11^{\prime} 44^{\prime \prime} \mathrm{W}\right)$, during February 2006 and 2007. Large, mature specimens were collected by carefully digging with flat pronged forks and then removing the animals by hand. Specimens were returned to the laboratory and stored at $12^{\circ} \mathrm{C}$ in individual containers in FSW. Sex and maturity of specimens was checked on return to the laboratory by the examination of a coelomic sample collected with a $1 \mathrm{ml}$ syringe fitted with a $21 \mathrm{~g}$ hypodermic needle inserted between the segments in the posterior of the worm. Animals were maintained in individual glass aquarium tanks containers in well aerated FSW until use. 


\subsection{Weathering of crude oil and production of WAF:}

Exposure solutions containing the water accommodated fraction (WAF) of crude oil were prepared under controlled temperature conditions (at $12{ }^{\circ} \mathrm{C}$ ) according to a previously developed method (Scarlett et al., 2007; Smith et al., 2006). This method for generating WAF has been robustly tested and demonstrated to generate highly reproducible WAF in terms of its chemical composition, and for which the changes in chemical composition over time for a number of conditions has been thoroughly analysed and described (Smith et al., 2006). Fresh Forties crude oil was artificially weathered to simulate losses of the volatile (e.g. BTEX) components of the crude oil (representing approximately $20 \%$ of the hydrocarbon content) that would typically occur during the first 2-3h at sea following an oil spill. Twenty five millilitres of this weathered Forties crude oil was then slowly vortex mixed with $2475 \mathrm{~mL}$ of $36 \mathrm{psu}$ filtered $(0.2 \mu \mathrm{m})$ seawater at a ratio of 1:99 for 24 hours, and then left to re-equilibrate for one hour. After this mixing the clear solution of the water available fraction (WAF) was carefully siphoned off under low nitrogen pressure. Since WAF should contain the soluble components of the oil with minimal presence of droplets, the number of particles present in various size categories counted using a Beckman Z2 Coulter Particle Count and Size Analyser, and compared with that of seawater. WAFs were considered acceptable with particle counts $<5 \mathrm{x}$ that of seawater (which represents twice the standard deviation observed for natural seawater samples). For the exposures WAF was used as $100 \%$, or diluted with $0.2 \mu \mathrm{m}$ filtered seawater (FSW) to give $10 \%$ WAF and $1 \%$ WAF treatment solutions, made up immediately prior to use. 


\subsection{WAF chemical analysis}

WAF samples were taken in triplicate at time $=0$ and after 24 hours exposure time, prior to the water changes for the exposure treatments. WAF in seawater samples (40 $\mathrm{ml}$ ) were extracted using solid phase extraction (SPE) tubes (SPE Supelclean Envi ${ }^{\mathrm{TM}}$ 18, Supelco Bellefonte, USA). After transfer of the water samples into the SPE tubes, extracts were eluted with $5 \mathrm{~mL}$ of hexane: dichloromethane (1:1) and then evaporated to $0.7 \mathrm{~mL}$ over an ice bath to minimize loss of semi-volatile loss molecular weight PAH.

Deuterated alkanes (C10 d22, C19 d40 and C30 d62) and PAH (naphthalene d8, anthracene d10, chrysene d12 and perylene d12) internal standards were added to extracts at $0.5 \mu \mathrm{g} \mathrm{mL}^{-1}$ and $0.4 \mu \mathrm{g} \mathrm{mL}^{-1}$, respectively. PAH were identified and quantified by GC-MS using a Thermo Trace GC gas chromatograph coupled to a Thermo Trace DSQ ${ }^{\circledR}$ mass spectrometer operated at $70 \mathrm{eV}$ in positive ion mode. Chromatography was performed with a fused silica capillary column $(30.0 .25 \mathrm{~mm}$ internal diameter) coated with RTX®-5MS (0.25 $\mu \mathrm{m}$ film thickness; Restek Corporation, UK) with helium as the carrier gas. Splitless injection with a sample volume of $1 \mu \mathrm{L}$ was applied. The oven temperature was programmed at $65^{\circ} \mathrm{C}$ for 2 min and then increased to $310^{\circ} \mathrm{C}$ at $20^{\circ} \mathrm{C} \mathrm{min}^{-1}$ and held at this temperature for 30 min. The mass spectrometer was operated using the full scan mode (range $m / z$ 50650) for quantitative analysis of target saturated hydrocarbons and PAHs. For each compound, quantification was performed by integrating the peak at a specific $m / z$ ratio. External multilevel calibrations were carried out PAH quantification ranging from 0.005 to $0.5 \mathrm{ng} \mu \mathrm{L}^{-1}$ and from 0.010 to $1.0 \mathrm{ng} \mu \mathrm{L}^{-1}$, respectively. Major hydrocarbons in WAF were identified on the basis of their retention time and by comparing them with those of analytical standards. Analytes of WAF were 
normalized to the conservative biomarker $17(\mathrm{H}), 21(\mathrm{H}) \mathrm{C} 30$-hopane naturally present in crude oil (Prince et al., 1994).

For quality control, a $2.0 \mathrm{ng} \mu \mathrm{L}^{-1}$ diesel standard solution (ASTM C12-C60 quantitative, Supelco) and a $1.0 \mathrm{ng} \mu \mathrm{L}^{-1} \mathrm{PAH}$ Mix Standard solution (Supelco) were analyzed every 15 samples. The variation of the reproducibility of extraction and quantification of water samples were determined by successive extractions and injections $(n=6)$ of the same sample and estimated to be $\pm 8 \%$.

\subsection{Collection of Gametes:}

Mature Arenicola marina oocytes were collected through the injection of homogenised prostomia from donor females (according to the method of Bentley \& Pacey, 1992) into five gravid females, approximately equivalent of one prostomium per female. Females were injected the night before they were needed then left overnight in FSW at $12^{\circ} \mathrm{C}$. Any spawned oocytes were collected into microcentrifuge tubes for each female, washed using FSW and left to settle. Sperm maturation was induced though the injection of $8,11,14$-eicosatrienoic acid $\left(13 \mu \mathrm{g} \mathrm{g}^{-1}\right.$ of body mass) directly into the coelomic cavity of the male $\underline{A \text {. marina }}$ specimens (Bentley \& Pacey, 1992). Spawning usually followed approximately 1 hour after injection. Sperm was collected 'dry' as it was extruded from the nephromixia, to prevent it from becoming activated prior to use, and stored in micro-centrifuge tubes on ice until use for no more than 1 hour.

For Nereis virens, mature oocytes and sperm were removed using a $1 \mathrm{~mL}$ syringe fitted with a $21 \mathrm{~g}$ hypodermic needle inserted between the segments in the posterior of the worm. Sperm were assessed for motility under a compound light microscope and 
a fertilization test was conducted using active sperm to assess maturity of the gametes. After 10 minutes oocytes were observed and the presence of a jelly coat signified that the oocytes has been fertilized and so could be used for these experiments. Only males with highly active sperm were used. Gametes were then collected into microcentrifuge tubes and stored on ice until use for no more than 1 hour.

\subsection{Exposures and Fertilizations:}

Fertilizations were conducted according to the method of Lewis et al. (2002) with minor modifications. The density of settled oocytes for each female was determined by counting micro-volumes (three replicates of $2 \mu \mathrm{L}$ for each female) under a compound microscope. Sperm concentrations for each male were determined using a haemocytometer. Optimum sperm concentration and sperm: egg ratio of $10^{6}$ sperm per $\mathrm{ml}$ and $10^{4}$ sperm per oocyte (as determined by Williams, 1998) were used, except for the experiment looking at the effects of sperm concentration (in accordance with the suggestions of Marshall, 2006).

The water accommodated fraction of oils can be a highly complex mixture of different compounds and in initial experiments, the effects of individual polycyclic aromatic hydrocarbons on fertilization success was tested to afford a comparison. The isomers pyrene and fluoranthene were chosen since they are both common components of oil, both are readily soluble yet they differ in their reported toxicity, with fluoranthene listed as a priority pollutant (US EPA) due to its carcinogenic properties. Both compounds were tested (nominal concentrations of 25, 50, 100 and $200 \mu \mathrm{g} \mathrm{L}^{-1}$ ) using the methods described below and LOECs of $25 \mu \mathrm{g} \mathrm{l}^{-1}$ for fluoranthene and $100 \mu \mathrm{g} \mathrm{L}^{-1}$ for pyrene were calculated. A single nominal concentration of fluoranthene of $25 \mu \mathrm{g}$

$\mathrm{L}^{-1}$ was subsequently included as a positive control. Both fluoranthene and pyrene 
require solvent carriers to dissolve in seawater [unlike WAF], therefore an acetone carrier was used to make up the treatment solution to a final concentration of $0.01 \%$ solvent. This was then also used as an additional 'solvent' control at a concentration of $0.01 \%$ in seawater.

A volume equivalent to 1000 spawned oocytes was pipetted into Petri-dishes containing $10 \mathrm{~mL}$ of treatment solution (1\% WAF, 10\% WAF, 100\% WAF or FSW control), previously maintained at $12^{\circ} \mathrm{C}$. Five exposure dishes (one per female used) plus a no-sperm control were used per treatment. Sperm was pooled equally (according to concentration) from three-five males, then a volume equivalent to $10^{7}$ sperm added to each Petri-dish, giving a sperm: oocyte ratio of $10^{4}$ sperm per oocyte and a final concentration of $10^{6}$ sperm $\mathrm{mL}^{-1}$. The Petri-dishes were then placed into environmental cabinets at $12^{\circ} \mathrm{C}$ for ten minutes before being removed and the oocytes carefully washed with treatment solution $\left(\right.$ at $\left.12^{\circ} \mathrm{C}\right)$. All oocytes were washed twice with treatment solution and then returned to the environmental cabinets. Twenty four hours after fertilization, samples of oocytes/embryos were taken from each dish, fixed in 5\% ethanol in seawater, and observed under a compound microscope. Fifty oocytes/embryos per replicate were scored as being fertilized/not fertilized according to the presence absence of a fertilization membrane, and their developmental stage recorded.

\subsection{Early Larval Survivorship}

Larval survivorship trails were conducted to compare the effect of WAF on Nereis virens survival in larvae from fertilizations in clean seawater (i.e. exposed during early development only) and those from fertilizations in the WAF treatments (i.e. exposed during fertilization and early development). Fertilizations were conducted as 
described above, using oocytes pooled from two females per replicate and from 6 females in total (i.e. three replicates). Sperm was pooled from four males.

Fertilizations were conducted in 1\% WAF, $10 \%$ WAF, $100 \%$ WAF or FSW treatment solutions and maintained in these at $12^{\circ} \mathrm{C}$ for 12 hours. Embryos/larvae were then transferred to wells of a 12 -well glass plate at a density of 10 embryos/larvae per well, in $1 \mathrm{ml}$ of the same treatment solution (with three replicate plates per treatment). Embryo/larvae from fertilizations in FSW were also plated out into 1\% WAF, $10 \%$ WAF, and $100 \%$ WAF exposure solutions along with a control FSW treatment. Larvae were fed a drop of dilute Isochyrsis sp. solution once they had reached the first feeding stage (determined visually as movements of the pharynx). Treatment solutions were changed every day for freshly made WAF or FSW. Survivorship was determined by counting the number of dead/alive embryos/larvae at time intervals throughout the exposure period, by observing the plates under a dissecting microscope. The exposure ran for 10 days in the 'development only' experiment, but was terminated after only 5 days in the 'fertilization and development' experiment due to all of the $100 \%$ WAF exposure animals dying.

\subsection{Fluctuating Asymmetry Measurement in Nereis virens:}

Effects of WAF exposure on developmental stability in Nereis virens nechtochaete larvae were measured using an analysis of fluctuating asymmetry (FA). This was conducted according to the method of Lewis et al. (2004) at 7 days post-fertilization. Embryos from the fertilizations conducted in section 2.5 were transferred to $2 \mathrm{~L}$ glass beakers 24 hrs post-fertilization, and reared in their treatment solutions to the three setiger nechtochaete stage at $12^{\circ} \mathrm{C}$. Five to ten larvae at a time were pipetted carefully onto a microscope slide, using a Pasteur pipette, and a cover slip was placed gently on top. As the FSW started to evaporate from the slide, the cover slip compressed the 
larvae slightly, allowing measurements to be taken from those lying ventral-side down. Larvae lying on their sides or dorsal surface were ignored. Fifty larvae from each treatment were measured for FA of three traits. Larvae were measured at the three-setiger stage, as this is the earliest stage at which distinct left and right characters can easily be measured. Left and right measurements were taken for eyespot diameter, peristomial cirri length and anal cirri length, for each individual. The analysis of the FA index in Nereis virens larvae was conducted using the procedures outlined by Lewis et al. (2004), which first confirm that any deviations from symmetry measured in the larvae conform to the requirements for FA, and then calculates an FA index for each individual larva by taking the average FA of the three traits measured.

\subsection{Statistics:}

The arcsine transformation was used to normalise data initially described as percentage fertilization success to enable to the use of parametric statistics. Bartlett's and Levene's tests were used to check for homogeneity of variance between treatments for each experiment. One-way and two way ANOVAs were then performed to compare treatments. A posteriori analysis was then performed using Fisher's Pairwise Comparisons using the procedures available in the statistical package Minitab (Minitab Inc.). For the larval survivorship data a non-parametric Kruskall-Wallis test was used due to the low sample size used. A P value of $<0.05$ was used for rejection of the null hypothesis. 


\section{Results}

\subsection{WAF chemical analysis:}

Freshly made WAF $\left(\right.$ time $=0 \mathrm{~h}$ ) contained $2 \mathrm{mg} \mathrm{L}^{-1}$ PAHs consisting mostly of the volatile BTEX (benzene, toluene, ethylbenzene and xylenes) compounds. After twenty four hours in the exposure conditions the oil content of WAF treatment solutions were dominated by naphthalenes. The volatile BTEX compounds evaporate rapidly and were absent after 24 hours. Total naphthalenes measured in the $100 \%$ WAF samples were $0.38 \mathrm{mgL}^{-1}$, comprising naphthalene $\left(0.18 \mathrm{mgL}^{-1}\right)$; $\mathrm{C} 1$ naphthalenes $\left(0.15 \mathrm{mgL}^{-1}\right)$ and $\mathrm{C} 2$-naphthlenes $\left(0.05 \mathrm{mgL}^{-1}\right)$. No other individual PAHs could be identified in the samples.

\subsection{Effect of WAF on fertilization success:}

Fertilization success in Arenicola marina was significantly reduced by exposure to both the individual polycyclic aromatic hydrocarbons (PAHs) pyrene (Figure 1a) and fluoranthene (Figure 1b) and by the water accommodated fraction of crude oil (WAF), (Figure 1b). In the pyrene exposure post hoc analysis revealed fertilization success was significantly reduced from the FSW control at all concentrations used (one way ANOVA, $\mathrm{F}_{5,29}=5.44, \mathrm{P}<0.001$ ), with percentage fertilization reduced to $71.33 \%$ at the highest concentration of $200 \mu \mathrm{g} \mathrm{L}^{-1}$. There was no significant difference between the seawater and solvent controls. The effect of WAF was greater, with a significant reduction in fertilization success compared to the controls at all exposure concentrations (one-way ANOVA, $\mathrm{F}_{5,29}=17.45, \mathrm{P}<0.001$ ) with an average of only $26.8 \%$ of oocytes showing signs of fertilization at the highest WAF concentration (a significant reduction compared to the other WAF exposure concentrations). 
In the Nereis virens experiment using optimal sperm concentration (Figure 2a), post hoc analysis revealed that fertilization success was significantly reduced in all of the WAF exposure treatments compared to the controls (one-way ANOVA, $\mathrm{F}_{5,53}=21.12$, $\mathrm{P}<0.001)$. Fertilization success in the $100 \%$ WAF treatment was significantly lower than in the $1 \%$ and $10 \%$ WAF treatments. This reduction in fertilization success was not as great as in Arenicola marina however, with an average $76 \%$ fertilization success recorded in the $100 \% \mathrm{WAF}$ treatments. In the experiments measuring fertilization success in Nereis virens at varying sperm concentrations exposed to $100 \%$ WAF (Figure 2b), a significant effect of sperm concentration and WAF exposure on fertilization success was observed (two-way ANOVA; for sperm concentration: $F_{5,35}=29.79, P<0.01$; for WAF exposure: $F_{1,35}=298.16, P<0.01$ [with no significant interaction term]). Maximum fertilization success in FSW was measured at a sperm concentration of $10^{6}$ sperm per $\mathrm{mL}$, with fertilization success dropping off at higher sperm concentrations. In the $100 \%$ WAF treatment, no fertilization was observed at a sperm concentration of $10^{3}$ sperm per $\mathrm{mL}$, and fertilization success was very low at the low sperm concentrations. At the highest sperm concentration used of $10^{8}$ sperm per mL fertilization success was still increasing, the optimum sperm concentration not having been reached. Fertilization success in exposures from this second experiment were generally much lower than the initial experiment at optimal sperm concentration. These experiments were conducted using different individuals during separate breeding seasons (i.e. a year apart) which may account for the observed differences in susceptibility to WAF exposure.

\subsection{Effect of WAF on Post-Fertilization Development:}

No significant effect of WAF on the percentage of Arenicola marina embryos developing normally 24 hours post fertilization (Figure 3a), was observed (one-way 
ANOVA, $\left.\mathrm{F}_{5,29}=2.05, \mathrm{P}=0.108\right)$. These measurements were made on surviving embryos from the fertilization experiments (100 oocytes/embryos were observed for each replicate and the developmental stage of those that were still alive was noted), however, and there were very few of these at the higher WAF concentrations which may have affected these results. A significant effect of WAF on post-fertilization development was observed in Nereis virens (one-way ANOVA, F $5,53=22.32, \mathrm{P}<$ 0.001), with significant abnormalities (abnormal cleavage patterns and discoloration of embryos) observed in the $10 \%$ and $100 \%$ WAF concentrations and in the fluoranthene treatment (Figure 3b).

A noticeable affect of WAF on development rates in Arenicola marina (Figure 4) was observed 24 hours post-fertilization. In the FSW and solvent control treatments $24 \%$ $-43 \%$ of the surviving embryos were at the swimming trochophore stage after 24 hours, but no trochophores were present in any of the WAF treatments after the same time interval. A slight reduction in cleavage rate was also observed in the solvent control treatment compared to the FSW control, but these embryos appeared to "catch up' with the FSW control embryos by the end of this experimental period. All of the surviving embryos in the WAF treatments were still undergoing cleavage, having not yet reached the blastula stage.

\subsection{Early Larval Survivorship}

The effects of WAF on early larval survivorship in Nereis virens larvae resulting from (a) fertilizations in FSW (i.e. development only in WAF) and (b) fertilizations in WAF (i.e. fertilization and development in WAF) are shown in Figures 5a and 5b. Exposure to WAF significantly reduced survivorship in both experiments, however this effect was much greater in the larvae for which fertilization also occurred in the 
WAF treatments. In the larvae from fertilizations in FSW, i.e. exposed during early development only (Figure 5a), survivorship was reduced to $55.6 \%$ in the $100 \%$ WAF treatment, and was significantly reduced in all three WAF treatments compared to the FSW control at the end of the 10 day exposure period (Kruskal-Wallis: $\mathrm{H}=9.14, \mathrm{P}=$ 0.027).

In the larvae exposed to WAF during both fertilization and early development (Figure 5b), there was a highly significant effect of WAF exposure on larval survivorship (Kruskall-Wallis: $\mathrm{H}=10.38, \mathrm{P}=0.015$ ). In the $100 \%$ WAF treatment $100 \%$ mortality was observed at 5 days, and survivorship was much lower in the $10 \%$ and $1 \%$ WAF treatments compared to those from the 'development only' experiment..

\subsection{Fluctuating Asymmetry in Nereis virens:}

A significant increase in mean fluctuating asymmetry index was observed in $\underline{\text { Nereis }}$ virens nechtochaetes reared in all three WAF treatments (one-way ANOVA, F $\mathrm{F}_{3,11}=$ 9.06, $\mathrm{P}<0.01)$. There was no dose-dependant response however, with the highest FA measured in the $1 \%$ WAF treatment (Figure 5c).

\section{Discussion}

These results illustrate the potential impacts of soluble oil components on the reproductive success of two ecologically important polychaete species. Fertilization success in both Arenicola marina and Nereis virens was significantly reduced in the presence of the water accommodated fraction of crude oil (WAF) at all exposure concentrations, but with differences in sensitivities observed between the two species. The reduction in fertilization success observed in Nereis virens when exposed to the 
WAF treatments was much less than the reduction in fertilization success observed for Arenicola marina. The Nereis virens specimens used in these experiments were collected from a site known to contain fairly high levels of PAHs in the sediment (Environment Agency 2007 data) and the adults have been shown to have high levels of DNA damage in their somatic cells (Lewis \& Galloway, 2008). Nereis virens are generally considered to be fairly tolerant to PAH contaminated conditions (e.g. De Boeck \& Kirsch-Volders, 1998; Stark et al., 2003), however the results presented here suggest that their reproductive biology is still vulnerable to disruption through PAH exposure. The Arenicola marina specimens used here were collected from a site relatively free from contamination (Environment Agency 2007 data), and the data presented here agrees with previous suggestions that this species is more sensitive to damage from PAH exposure (Lewis \& Galloway, 2008).

These results, in particular, highlight the sensitivity of low density, sperm-limited populations to pollution events. When sperm concentrations approximate to those measured under field conditions during natural spawning events were used in $\underline{\text { Nereis }}$ $\underline{\text { virens, }}$, however, fertilization success was dramatically reduced. In a study of field fertilization rates in Arenicola marina (Williams et al., 1997) sperm concentration was observed to peak briefly at $10^{6}$ sperm $\mathrm{mL}^{-1}$ over a short period but was measured at $10^{4}$ sperm $\mathrm{mL}^{-1}$ over a period of more than 2 hours. Field measurements of fertilization success for Nereis virens have been reported as being highly variable but typically around 50\% (Williams, 1998). This level of fertilization success in the laboratory was achieved by sperm concentrations of $10^{5}$ sperm per mL, suggesting this value is the typical sperm density during natural spawning events. In these laboratory WAF exposures using $\underline{N}$. virens, a sperm concentration of $10^{5}$ resulted in an average fertilization success of less than 5\%. WAF had a much greater effect on 
fertilization success at low sperm concentrations than at high sperm concentrations. Thus it can be postulated that an oil pollution event during reproduction would have the greatest effect on fertilization success in low density, sperm-limited populations. Effectively the WAF acted as to increase sperm dilution effects, most probably through impacts on sperm motility. Similar observations have been made regarding the impacts of copper pollution on fertilization success in the Australian polychaete Galeolaria caespitose (Hallows et al., 2007) and parental PAH exposures on sperm motility in Crassostrea gigas (Jeong and Cho, 2005).

WAF is a highly complex mixture that changes in chemical composition significantly over time when exposed to air and turbulent mixing due to the evaporative loss of the volatile BTEX compounds (e.g. Singer et al., 2000). The major constituent of WAF for the duration of the exposure period was the highly soluble bicyclic aromatic hydrocarbon naphthalene (also reported as the major constituent of WAF by Wolfe et al., 1998 and Barron et al, 1999). Previous and more sophisticated chemical analyses of WAF generated using the same technique as used in this study have additionally identified an unresolved complex mixture of PAHs (UCM) which cannot be resolved into individual compounds and the toxicity of which remains unclear (Scarlett et al., 2007; Smith et al., 2006). Recent field measurements from a real, relatively minor oil spill disaster on the South West Coast of the UK revealed similar findings with naphthalene forming one of the major PAHs measured in the surface micro-layer of the affected seawater (Guitart et al., 2008). Peak concentrations of soluble oil components in the water column of $5-10 \mathrm{mg} \mathrm{L}^{-1}$ were recorded after the Sea Empress disaster of 1996 (Sea Empress Environmental Evaluation Committee Final Report, 1998), making the concentrations used in these experiments relevant to a real spill situation. 
The evidence presented here points to sperm being the main target for the reproductive inhibitory effects of WAF exposure. The major mechanisms of toxicity of naphthalene include the production of reactive oxygen species (ROS), lipid peroxidation (Stohs et al., 2002), and causing cell membrane micro-viscosity (Bagchi et al., 1998). There is growing evidence from human health studies that oxidative stress reduces sperm functioning (e.g. Ochsendorf et al., 1998; Kasimanickam et al., 2007), and sperm straight line velocity has been shown to be significantly reduced in the presence of 1-naphthol, a metabolite of naphthalene (Meeker et al., 2004). Spermatozoa also have high polyunsaturated fatty acid content, making them highly susceptible to lipid peroxidation. This causes the plasma membrane to lose its fluidity and integrity, ultimately leading to loss of sperm function (Aitken et al., 1993). Loss of membrane fluidity also affects the cell membrane ion exchange that controls sperm movement (Rao et al., 1989). Toxicity effects on the oocyte prior to fertilization are also likely since membrane integrity is vital for sperm: egg recognition and membranes are generally targets for PAH related lipid peroxidation. Exposure to petroleum hydrocarbons has also been shown to cause lysosomal structure alterations in oocytes of the mussel Mytilus galloprovincialis (Cajaraville et al., 1991).

WAF exposure was found to have teratogenic effects on the early development stages of both $\underline{\text { Arenicola marina }}$ and Nereis virens. Development rates were slower in both species and a significantly higher level of developmental instability (measured as fluctuating asymmetry) was measured in $\underline{N \text { virens }}$ nechtochaetes exposed to the WAF treatments. The first 12 hours of exposure, comprising the fertilization reaction and the first 12 hours of post-fertilization development, appear to be the most sensitive stages to disruption, since embryos transferred from FSW to the WAF treatments after 
this time had much higher survivorship. These findings agree with those of Davis et al. (1981), who described the first 12 hours of development in the asteroid Patiria $\underline{\text { miniata }}$ as being the most sensitive to disruption though exposure to WAF. Sub-lethal effects that must have occurred during the first 12 hours of development appear to manifest themselves during subsequent larval development, as well as through increased mortality during the cleavage and gastrulation stages. Other studies using individual PAHs have described teratogenic effects on early development stages, including disruption of axial development in sea urchins (Pillai et al., 2003) and abnormal development in oyster larvae (Wessel et al., 2007).

Relating the impacts of WAF exposure on the reproductive biology of the two polychaetes measured here in laboratory conditions to population level effects that would occur in nature is complex. It is often hypothesised that reduced fertilization success rates and embryotoxicity would result in lower settlement rates and therefore reduced population growth, however larval mortality rates in free spawning marine invertebrates are naturally high and hence this is not a straightforward relationship. What can be deuced is that WAF exposure at the time of spawning has the effect of exaggerating sperm dilution effects. For species such as Nereis virens and Arenicola marina, which are heavily exploited for bait (e.g. Blake, 1979) and hence population densities may be low, this may have additional impacts on their fertilization ecology leading to many oocytes from a spawning episode remaining unfertilized.

\section{Conclusions}

These results illustrate how the presence of crude oil in its soluble form in seawater at the time of a spawning event for either Arenicola marina or Nereis virens could 
impact on fertilization success. Reductions in fertilization success rates are predicted from reduced sperm: egg collision rates, with additional teratogenic impacts on the resulting embryos and larvae. The fertilization stage is more sensitive than cleavage or early development stages for both species. N. virens in particular is often found in sediments affected by chronic PAH contamination and there is a clear research gap in our understanding of how this species is still able to survive in soft sediments heavily contaminated with hydrocarbons.

\section{Acknowledgements}

This work was funded by the European Commission through the FP6 FACEiT program (FP6-2004-Global-3.3.111.3.1), contract 018391. The authors would like to thank Trevor Worsey for technical support, and Alan Scarlett, Louis Peperzak and Kees Booij for their help with the chemical analysis.

\section{References}

Aitken, R.J., Harkiss, D., Buckingham, D.W., 1993. Analysis of lipid peroxidation mechanisms in human spermatozoa. Mol. Reprod. Dev. 35, 302-315.

Andronikov, V.B., 1975. Heat resistance of gametes of marine invertebrates in relation to temperature conditions under which the species exist. Mar. Bio. 30, $1-12$.

Bagchi, M., Bagchi, D., Balmoori, J., Ye, X., Stohs, S. J., 1998. Naphthalene-induced oxidative stress and DNA damage in cultured macrophage J774A.1 cells. Free Rad. Biol. Med. 25, 137-143. 
Barron, M.G., Podrabsky, T., Ogle, S., Ricker, R.W. 1999. Are aromatic hydrocarbons the primary determinant of petroleum toxicity to aquatic organisms? Aquat. Toxicol. 46, 253-268.

Bejarano, A.C., Chandler, G.T., He, L., Coull, B.C., 2006. Individual to population level effects of South Louisiana crude oil water accommodated fraction (WAF) on a marine meiobenthic copepod. J. Exp. Mar. Biol. Ecol. 332, 49-59.

Bentley, M.G., Pacey, A.A., 1992. Physiological and environmental control of reproduction in polychaetes, Oceanogr. Mar. Biol. Ann. Rev. 30, 443-481.

Blake, R.W., 1979. Exploitation of a natural population of Arenicola marina (L.) from the north east coast of England. J. Appl. Ecol. 16, 663-670.

Bonsdorff, E., Bakke, T., Pedersen, A. 1990. Colonization of amphipods and polychaetes to sediments experimentally exposed to oil hydrocarbons. Mar. Poll. Bull. 21, 355-358.

Bode, M., Marshall, D.J., 2007. The quick and the dead? Sperm competition and sexual conflict in sea. Evolution 61, 2693-2700.

Cajaraville, M.P., Marigomez, J.A., Angulo, E., 1991. Automated measurement of lysosomal structure alterations in oocytes of mussels exposed to petroleumhydrocarbons. Arch. Environ. Contam. Toxicol. 21 (3), 395-400.

Caspers H., 1984. Spawning periodicity and habitat of the Palolo worm Eunice viridis (Polychaeta, Eunicidae) in the Samoan Islands. Mar. Biol. 79, 229-236.

Couillard, C.M., Lee, K., Legare, B., King, T.L., 2005. Effect of dispersant on the composition of the water-accommodated fraction of crude oil and its toxicity to larval marine fish. Environ. Toxicol. Chem. 24, 1496-1504.

Cucci, T.L., Epifanio, C.E., 1979. Long-term effects of water-soluble fractions of Kuwait crude-oil on the larval and juvenile development of the mud crab Eurypanopeus depressus. Mar. Biol. 55, 215-220. 
Davis, P.H., Schultz, T.W., Spies, R.B. 1981. Toxicity of Santa Barbara seep oil to starfish embryos: Par 2- The growth bioassay. Mar. Environ. Res. 5, 287-294.

De Boeck, M., Kirsch-Volders, M., 1998. Nereis virens (Annelida, Polychaeta) is not an adequate sentinel species to assess the genotoxic risk comet assay) of PAH exposure to the environment. Environ. Mol. Mutat. 30, 82-90.

Denny, M.W., Shibata, M.F., 1989. Consequences of surf-zone turbulence for settlement and external fertilization. Amer. Nat. 134, 859-889.

Fischer, A., Schmitz, K., 1981. Preparation, properties, and composition of Nereis vitellin, the yolk protein of the Annelid, Nereis virens, Differentiation, 19, 103108.

Gaspari, L., Chang, S.S., Santella, R.M, Garte, S., Pedotti, P., Taioli, E., 2003. Polycyclic aromatic hydrocarbon-DNA adducts in human sperm as a marker of DNA damage and infertility. Mutat. Res.-Gen. Toxicol. Environ. Mut. 535, 155-160.

Goerke, H., 1984. Temperature dependence of swarming in North Sea Nereidae. In: Fischer, A. and Pfannenstiel H.D. (Eds.), Polychaete Reproduction, Gustav Fischer Verlag, Stuttgart, pp39-51.

Guest, J.R., Baird, A.H., Goh, B.P.L, Chou, L.M., 2005. Seasonal reproduction in equatorial reef corals. Invert. Reprod. Devel. 48 (1-3), 207-218.

Guitart, C., Frickers, P., Horrillo-Caraballo, J., Law, R.J., Readman, J.W., 2008. Characterization of sea surface chemical contamination after shipping accidents. Environ. Sci. Technol. 42 (7), 2275-2282.

Hallows, C.F., Johnston, E.L., Marshall, D.J., 2007. Copper reduces fertilization success and exacerbates the Allee effect. Mar. Ecol. Prog. Ser. 333, 51-60.

Harrison, P.L, 1994. The effects of oil pollutants on fertilization rates in the scleractinian coral Acropora tenius. In: Proceedings of the Joint Scientific 
Conference on Science, Management and Sustainability of Marine Habitats in the $21^{\text {st }}$ Century, p30. Conference Abstracts, Townsville, Australia.

Harrison, P.L, Babcock, R.C., Bull, G.D., Oliver, J.K., Wallace, C.C., Willis, B.C., 1984. Mass spawning in tropical reef corals. Science 223, 1186-1189.

His, E., Beiras, R., Seaman, M.N.L., 1999. The assessment of aquatic contamination: Bioassays with bivalve embryos and larvae. Adv. Mar Biol. 37, 75-96.

Hsu, P.C., Chen, I.Y., Pan, C.H., Wu, K.Y., Pan, M.H., Chen, J.R., Chen, C.J., Chang-Chien, G.P., Hsu, C.S., Liu, C.S., Wu, M.., 2006. Sperm DNA damage correlates to polycyclic aromatic hydrocarbon biomarkers in coke oven workers. Int. Arch. Occup. Environ. Health, 79, 349-356.

Jeong, W.G., Cho, S.M., 2005. The effects of polycyclic aromatic hydrocarbon exposure on the fertilization and larval development of the Pacific oyster, Crassostrea gigas. J. Shell. Res. 24, 209-213.

Johns, D.M., Pechenik, J.A., 1980. Influence of the water-accommodated fraction of No. 2 fuel oil on energetics of Cancer irroratus larvae. Mar. Biol. 55, 247-254. Kasimanickam, R., Kasimanickam, V., Thatcher, C.D., Nebel, R.L., Cassell, B.G., 2007. Relationships among lipid peroxidation, glutathione peroxidase, superoxide dismutase, sperm parameters and competitive index in dairy bulls. Theriogenology 76, 1004-1012.

Levitan D.R., 1995. The ecology of fertilization in free spawning invertebrates. In: McEdward L., (Ed.), Ecology of Marine Invertebrate Larvae, pp123-156. CRC Press Inc., Boca Raton.

Levitan D.R., Petersen, C., 1995. Sperm limitation in the sea. Trends Ecol. Evol. 10, 228-231. 
Lewis, C., Galloway, T.S., 2008. Genotoxic damage in Polychaetes: a study of species and cell-type sensitivities. Mutat. Res.-Gen. Toxicol. Environ Mutagen. $654,69-75$.

Lewis, C., Caldwell, G.S., Bentley, M.G., Olive, P.J.W., 2004. Effects of a bioactive diatom-derived aldehyde on developmental stability in Nereis virens (Sars) larvae: an analysis using fluctuating asymmetry. J. Exp. Mar. Biol. Ecol. 304, $1-16$.

Lewis, C., Olive, P.J.W., Bentley, M.G., Watson, G.J., 2002. Does seasonal reproduction occur at the optimal time for fertilization in the polychaetes

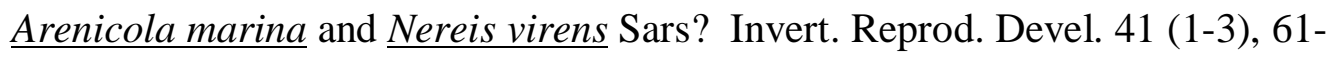
71.

Marshall, D.J., 2006. Reliably estimating the effect of toxicants on fertilization success in marine broadcast spawners. Mar. Poll. Bull. 52, 734-738.

Meeker, J.D., Ryan, L., Barr, D.B., Herrick, R.F., Bennet, D.H., Bravo, R., Hauser, R. 2004. The relationship of urinary metabolites of carbaryl/naphthalene and chlorpyrifos with human semen quality. Environ. Health Persp. 112 (17), 16651670.

Middaugh, D.P., Whiting, D.D., 1995. Responses of embryonic and larval inland silversides, Menidia beryllina, to No. 2 fuel oil and oil dispersants in seawater. Arch. Environ. Contam. Toxicol. 29, 535-539.

Negri, A.P., Heyward, A.J., 2000. Inhibition of fertilization and larval metamorphosis of the coral Acropora millepora (Ehrenberg, 1834) by petroleum products. Mar. Poll. Bull. 41, 7-12.

Ochsendorf, F.R., Buhl, R., Bastlein, A., Beschmann, H., 1998. Glutathione in spermatozoa and seminal plasma of infertile men. Human. Reprod. 13, 353359. 
Olive, P.J.W, Lewis, C., Beardall, V., 2000. Fitness components of seasonal reproduction: an analysis using Nereis virens as a life history model. Oceanol. Acta 23, 377-389.

Payne, J.R., Clayton, J.R., McNabb, G.D., Kirstein, B.E., 1992. Exxon Valdez oil weathering fate and behaviour: Model prediction and field observation. In: Proceeding of 1991 International Oil Spill Conference. Amer. Petr. Institute, Washington, DC.

Pennington, J.T., 1985. The ecology of fertilization of echinoid eggs- the consequences of sperm dilution, adult aggregation and synchronous spawning. Biol. Bull. 169, 417-430.

Pillai, M.C., Vines, C.A., Wikramanayake, A.H., Cherr, G.N., 2003. Polycyclic aromatic hydrocarbons disrupt axial development in sea urchin embryos through a beta-catenin dependent pathway. Toxicol. 186, 93-108.

Pollino, C.A., Holdway, D.A., 2002. Toxicity testing of crude oil and related compounds using early life stages of the crimson-spotted rainbowfish (Melanotaenia fluviatilis), Ecotox. Environ. Safety 52, 180-189.

Prince, R.C., Elmendorf, D.L., Lute, J.R., Hsu, C.S., Haith, C.E., Senius J.D., Dechert, G.J., Douglas, G.S., Butler E.L., 1994. 17-alpha(h),21-beta(h)-hopane as a conserved internal marker for estimating the biodegradation of crude-oil Environ. Sci. Technol. 28, 142-145.

Rao, B., Soufir, J.C., Martine, M., David, G., 1989. Lipid peroxidation in human spermatozoa as a related to midpiece abnormalities and motility. Gam. Res. 24, $127-134$.

Rossi, S.S., Anderson, J.W., 1976. Toxicity of water-soluble fractions of No. 2 fuel oil and South Louisiana crude oil to selected stages in the life history of the 
polychaete Neanthes arenaceodentata. Bull. Environ. Contam. Toxicol. 16, 1824.

Scarlett A., Rowland, S.J., Canty, M., Smith, E.L., Galloway, T.S., 2007. Method for assessing the chronic toxicity of marine and estuarine sediment-associated contaminants using the amphipod Corophium volutator. Mar. Environ. Res. 63, 457-470.

Schreiner, C.A., 2003. Genetic toxicity of naphthalene: A review. J. Toxicol. Environ. Health- B-Crit. Rev. 6, 161-183.

Singer, M.M., Aurand, D., Bragin, G.E., Clark, J.R., Coelho, G.M., Sowby M.L., Tjeerdema, R.S., 2000. Standardization of the preparation and quantitation of water-accommodated fractions of petroleum for toxicity testing. Mar. Poll. Bull. 40, 1007-1016.

Smith, E.L., Rowland, R.S., Galloway, T.S., Scarlett, A., 2006. Potential ecological effects of chemically dispersed and biodegraded oil: evaluation of components and concentrations relevant to policy decisions. Maritime and Coast Guard Agency UK Report no. 562, available online at http://www.mcga.gov.uk/c4mca/rp562_final_report.pdf

Stohs, S.J., Ohia, S., Bagchi, D., 2002. Naphthalene toxicity and antioxidant nutrients. Toxicology, 180, 97-105.

Stark, J.S., Snape, I., Riddle, M.J., 2003. The effects of petroleum hydrocarbon and heavy metal contamination of marine sediments on recruitment of Antarctic soft-sediment assemblages: a field experimental investigation J. Exp. Mar. Biol. Ecol., 283, 21-50.

Tracey, G.A., 1988. Feeding reduction, reproductive failure, and mortality in Mytilus $\underline{\text { edulis }}$ during the 1985 brown tide in Narragansett Bay, Rhode Island. Mar. Ecol. Prog. Ser., 50, 73-81 
Watson, G.J., Williams, M.E., Bentley, M.G., 2000. Can synchronous spawning be predicted from environmental parameters? A case study of the lugworm Arenicola marina. Mar. Biol. 136, 1003-1017.

Wessel, N., Rousseau, S., Caisey, F., Quiniou, F., Akcha, F. 2007. Investigating the relationship between embryotoxic and genotoxic effects of benzo(a)pyrene, $17 \alpha$-ethinylestradiol and endosulfan on Crassostrea gigas embryos. Aquat. Toxicol. 85, 133-142.

Williams, M.E., 1998. Assessment of fertilization success in broadcast spawners. PhD Thesis, School of Biological Sciences, University of St. Andrews, St. Andrews, U.K.

Williams, M.E., Bentley, M.G., Hardege, J.D., 1997. Assessment of field fertilization success in the infaunal polychaete Arenicola marina (L.). Invert. Reprod. Devel. 31, 189-197.

Wolfe, M.F., Schwartz, G.J.B., Singaram, S., Mielbrecht, E.E., Tjeerdema, R.S., Sowby, M.L., 1998. Influence of dispersants on the bioavailability of naphthalene from the water-accommodated fraction crude oil to the goldenbrown algae, Isochrysis galbana. Arch. Environ. Contam. Toxicol. 35, 274280.

Yund, P.O., 2000. How severe is sperm limitation in natural populations of free spawners? Trends Ecol. Evol. 15, 10-13. 


\section{Figure Legends:}

Figure 1: Effects of (a) pyrene and (b) the water accommodated fraction of crude oil (WAF) at varying concentrations on fertilization success in Arenicola marina. Data as mean \pm standard error $(n=5) . F S W=$ seawater control; a $0.01 \%$ acetone carrier was used to dissolve pyrene in seawater hence the need for an additional solvent control. N.B $*$ significantly different to FSW controls.

Figure 2: Effects of the water accommodated fraction of crude oil (WAF) on fertilization success in Nereis virens (a) at an optimum sperm concentration of $10^{6}$ per $\mathrm{mL}$ and (b) at varying sperm concentrations. Data as mean \pm standard error $(n=5)$. N.B $*=$ significantly different to controls.

Figure 3: Effect of the water accommodated fraction of crude oil (WAF) on post fertilization development in (a) Arenicola marina and (b) Nereis virens. Data as mean number of embryos observed to be developing normally 24 hours post-fertilization \pm standard error $(n=5)$. N.B $*=$ significantly different to controls.

Figure 4: Effect of the water accommodated fraction of crude oil (WAF) on development rates in Arenicola marina. Data as mean proportion of live embryos at each developmental stage 24 hours after fertilization, $(n=5)$. N.B. fert $=$ fertilization membrane present but no signs of cleavage; 2-cell through to 32 cell represents the stage of cleavage; Blast/gast $=$ embryo at either blastula or gastrula stage; troch. $=$ at the swimming trochophore stage.

Figure 5: Effects of the water accommodated fraction of crude oil (WAF) on Nereis virens larval development and survival: (a) development only in WAF; (b) fertilization and development in WAF; (c) developmental stability measured as fluctuating asymmetry, in nechtochaetes. N.B $*$ = significantly different to controls. 
(a)

(b)

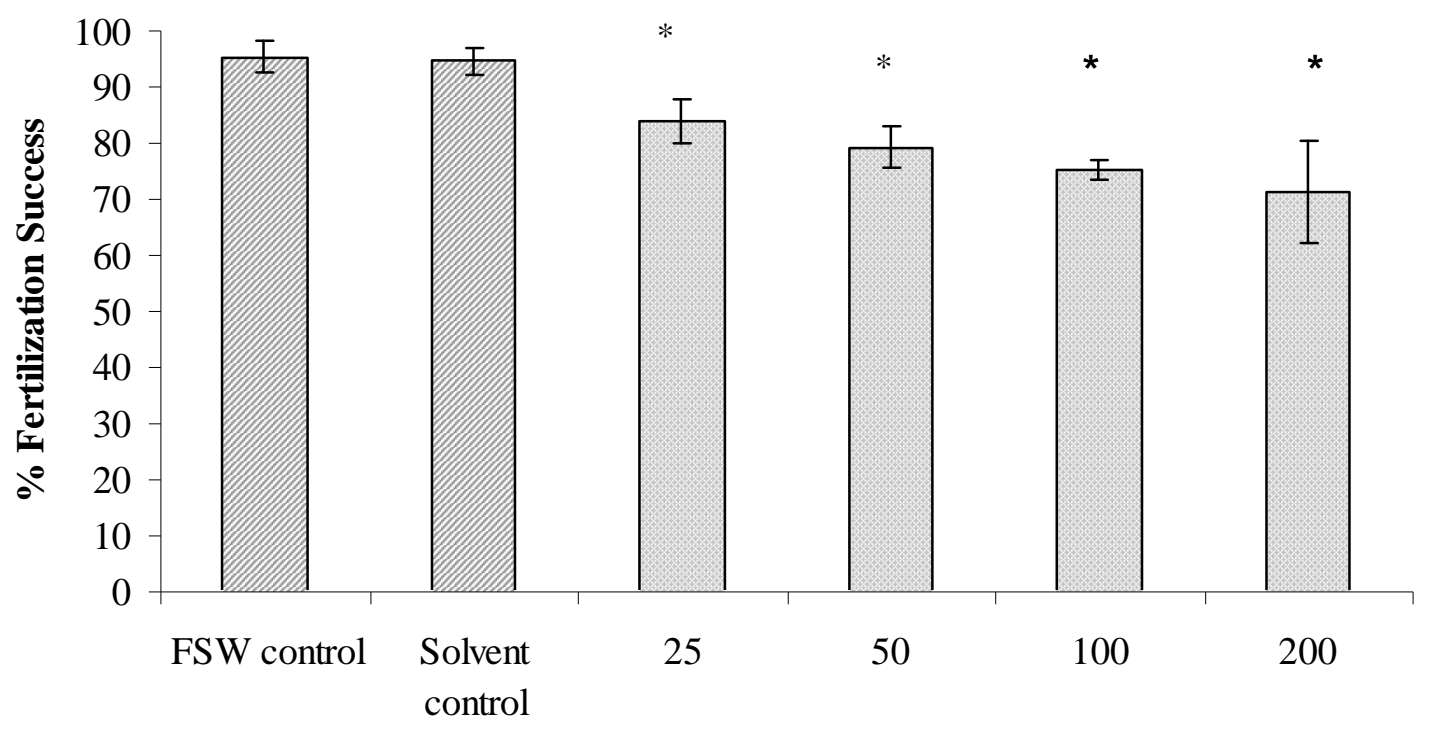

Pyrene Concentration ( $\mu \mathrm{gl}-1)$

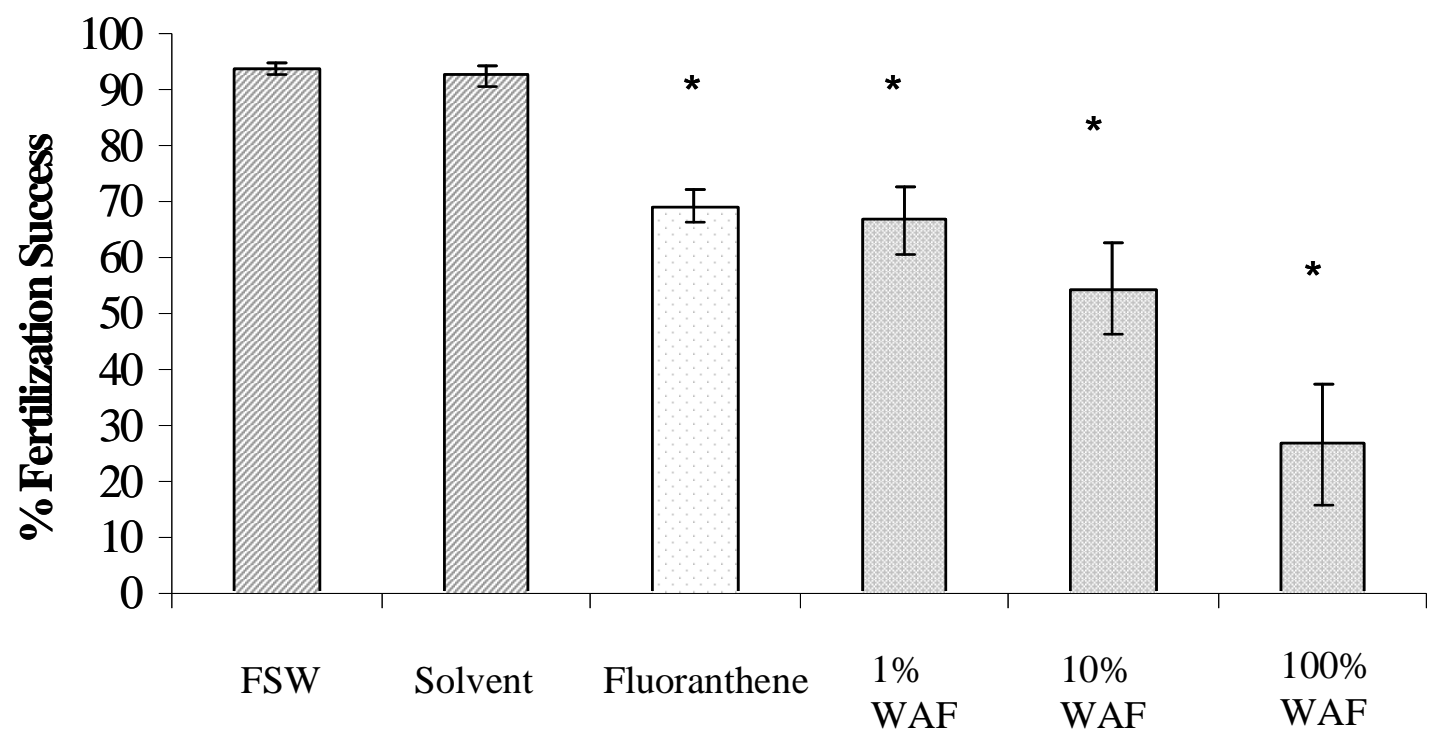


(a)
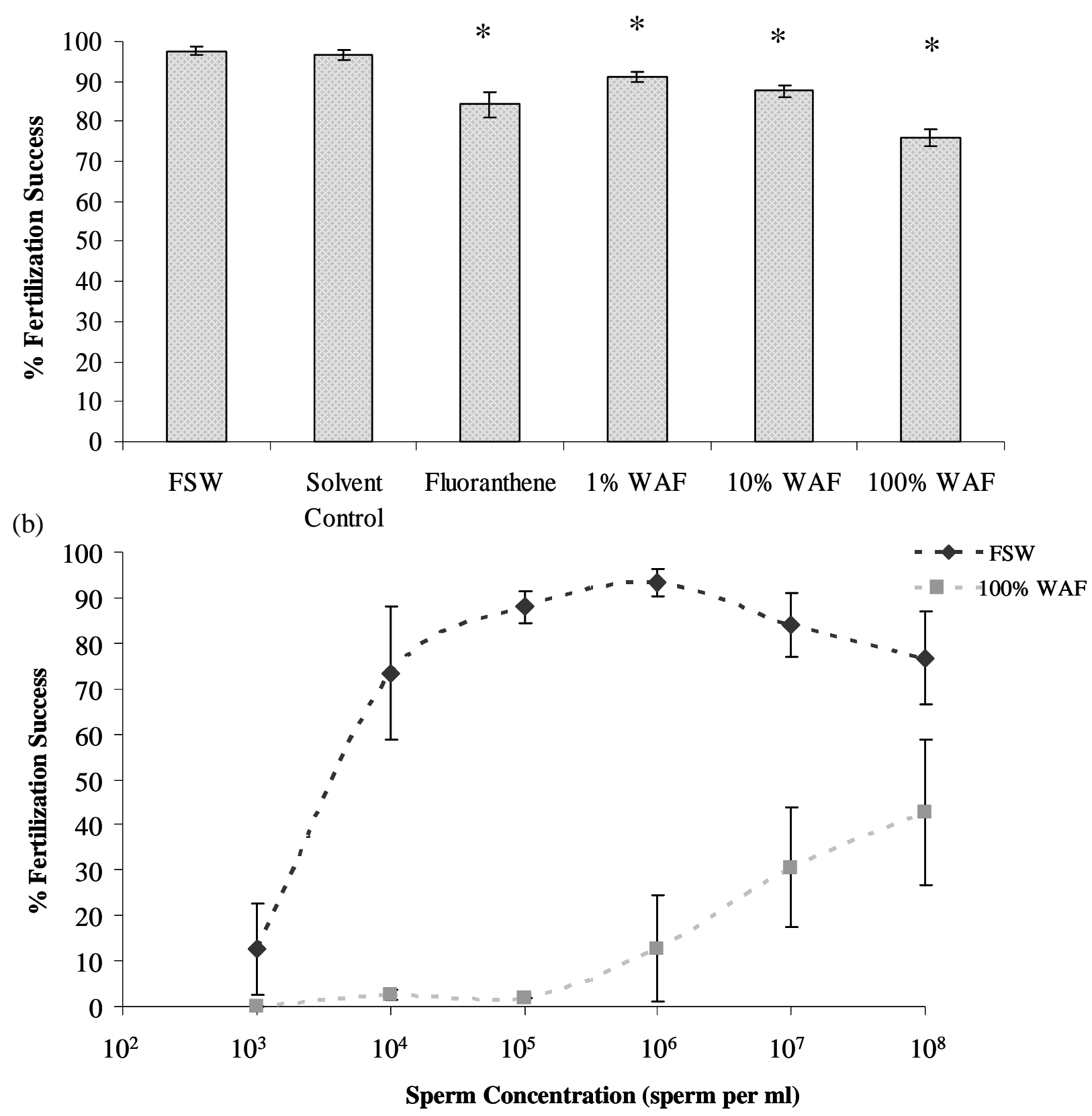
(a)

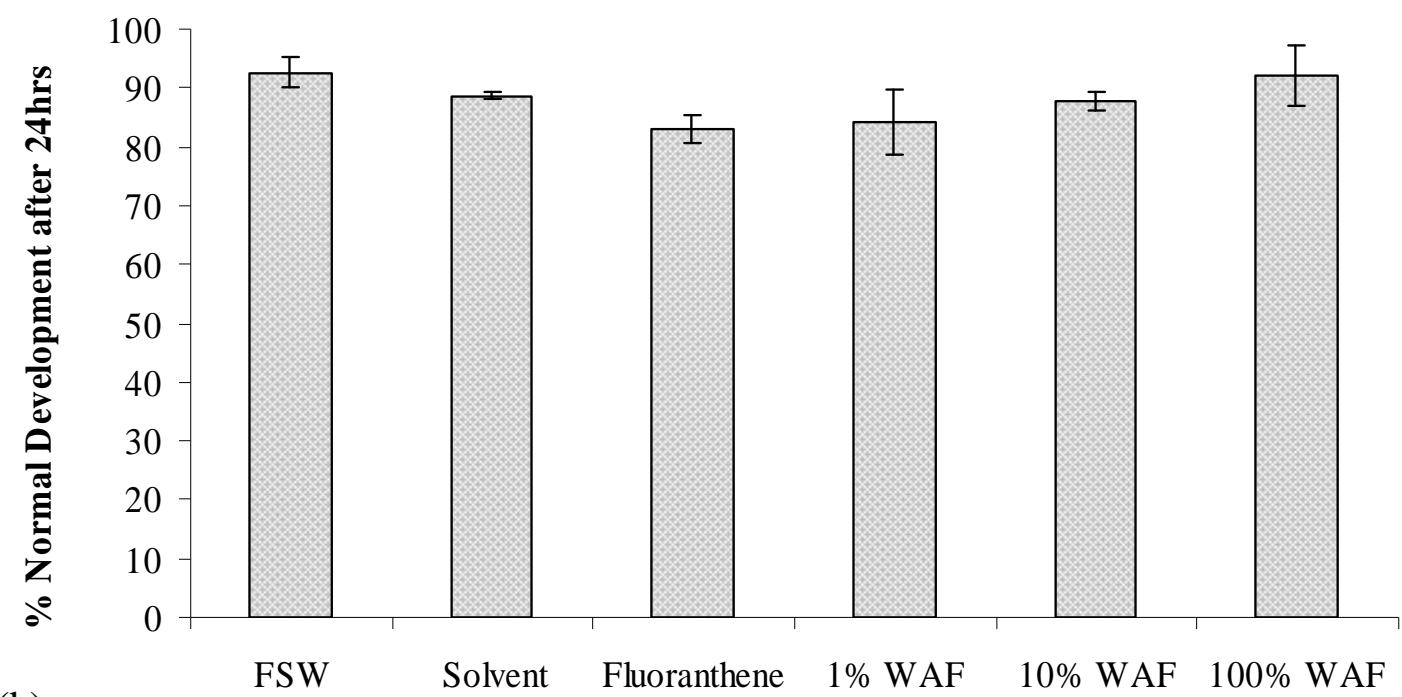

(b) Control

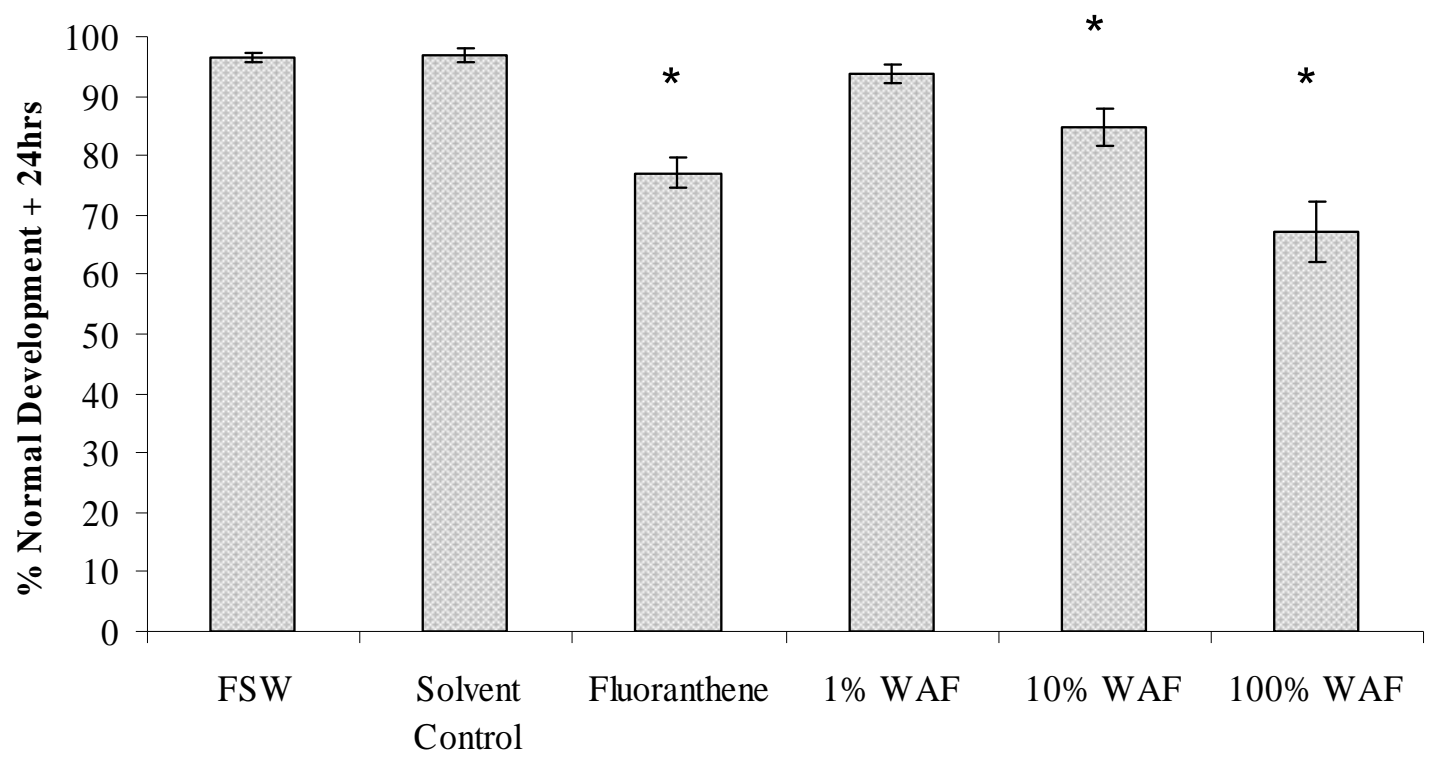




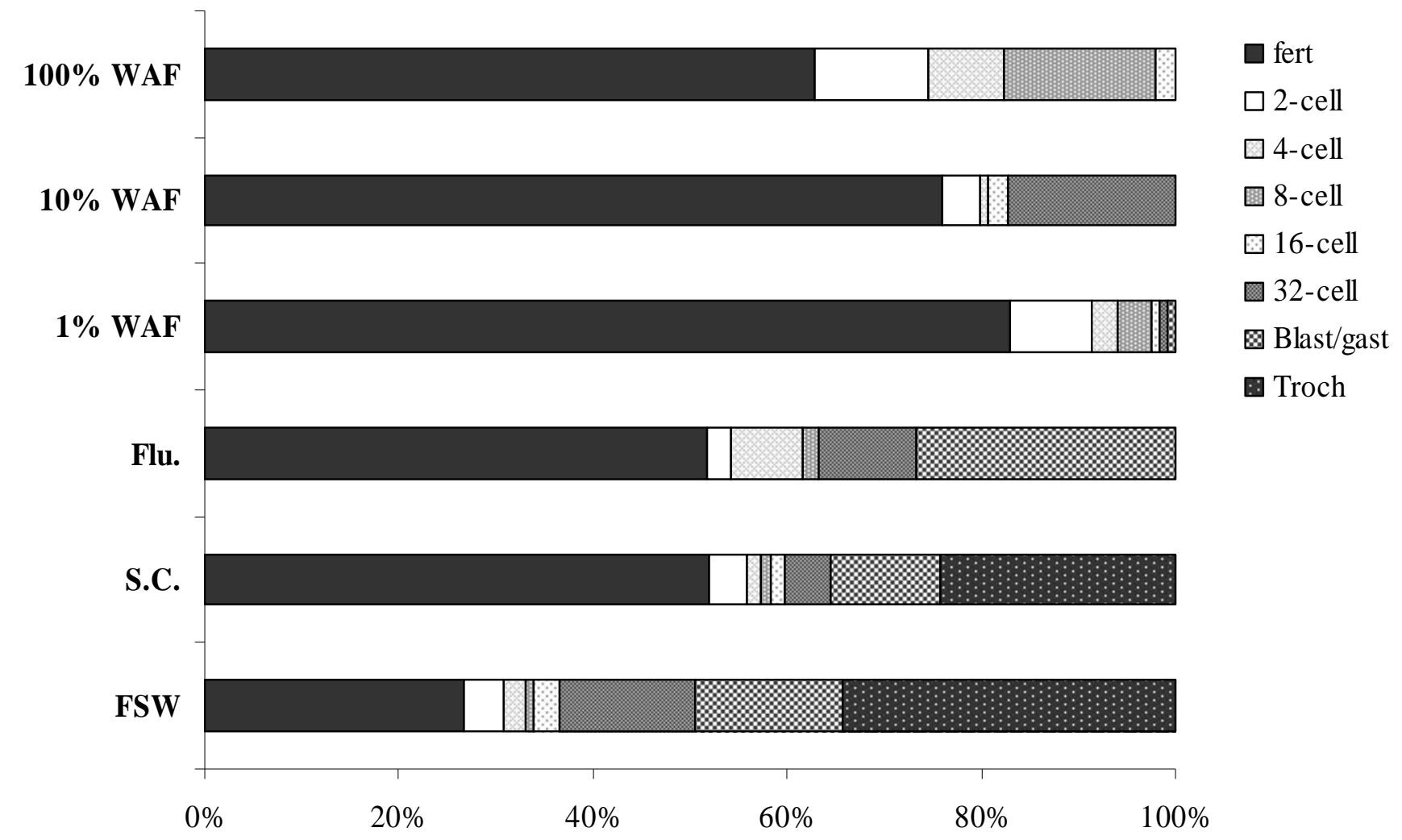

Development Stage (proportion of embryos) 
(a)

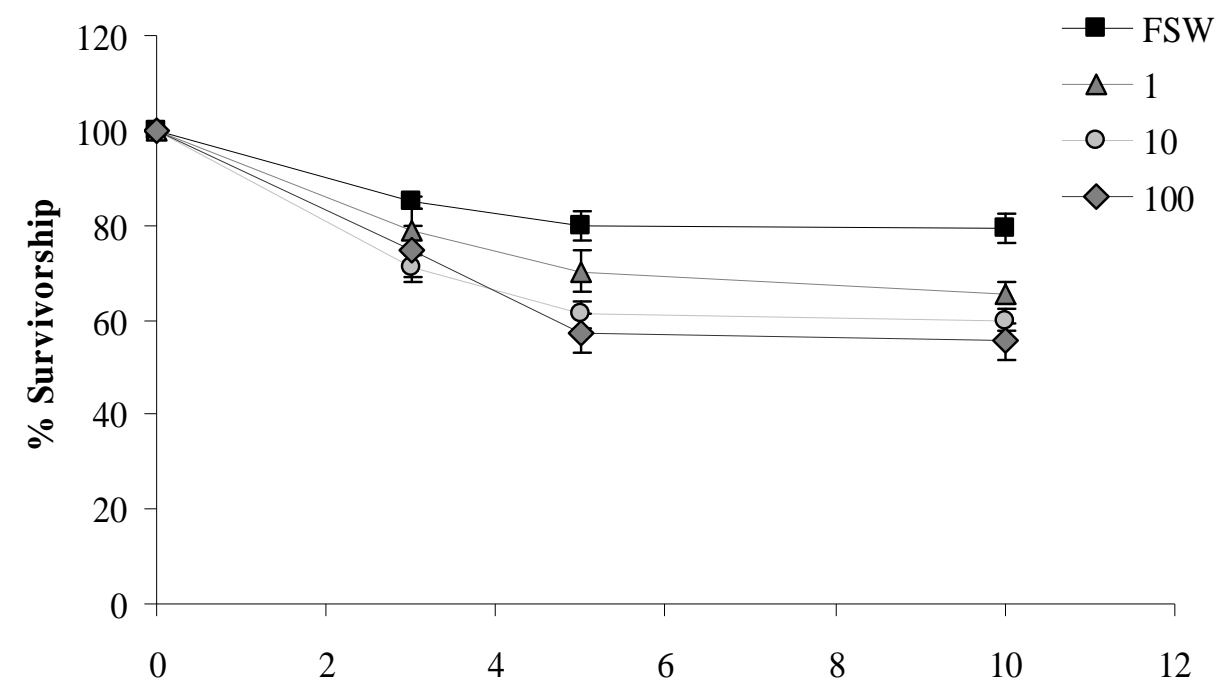

(b)

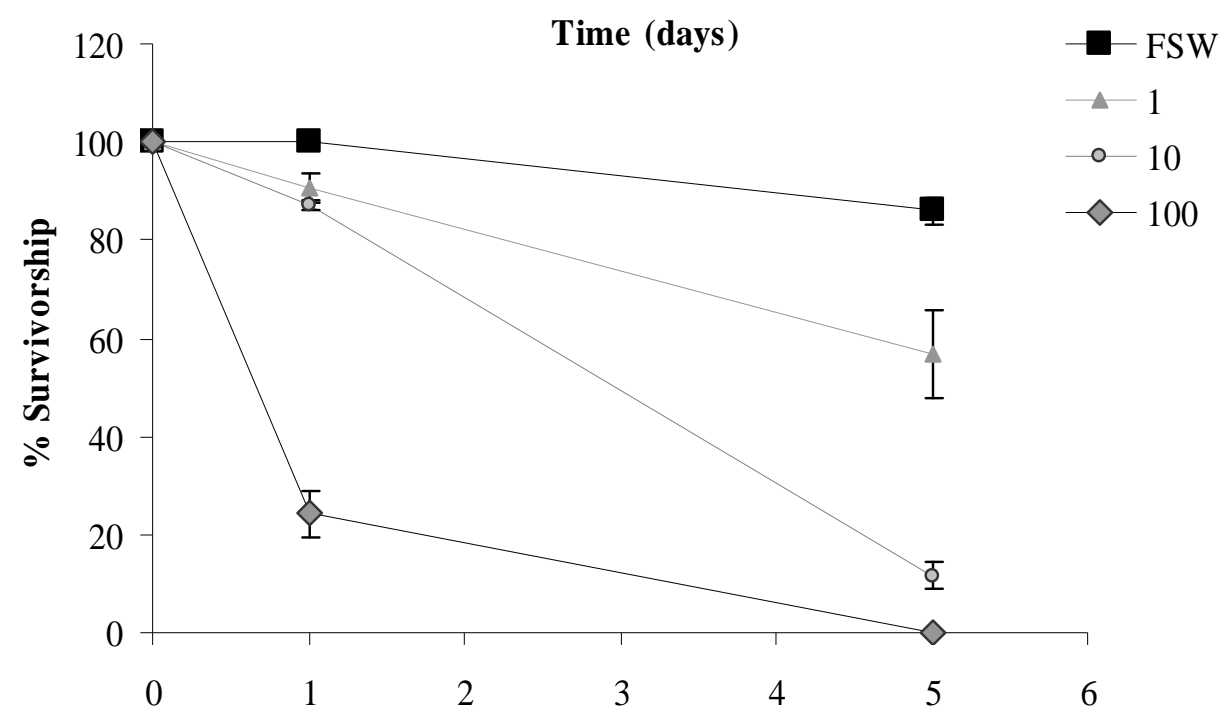

(c)

Time (days)

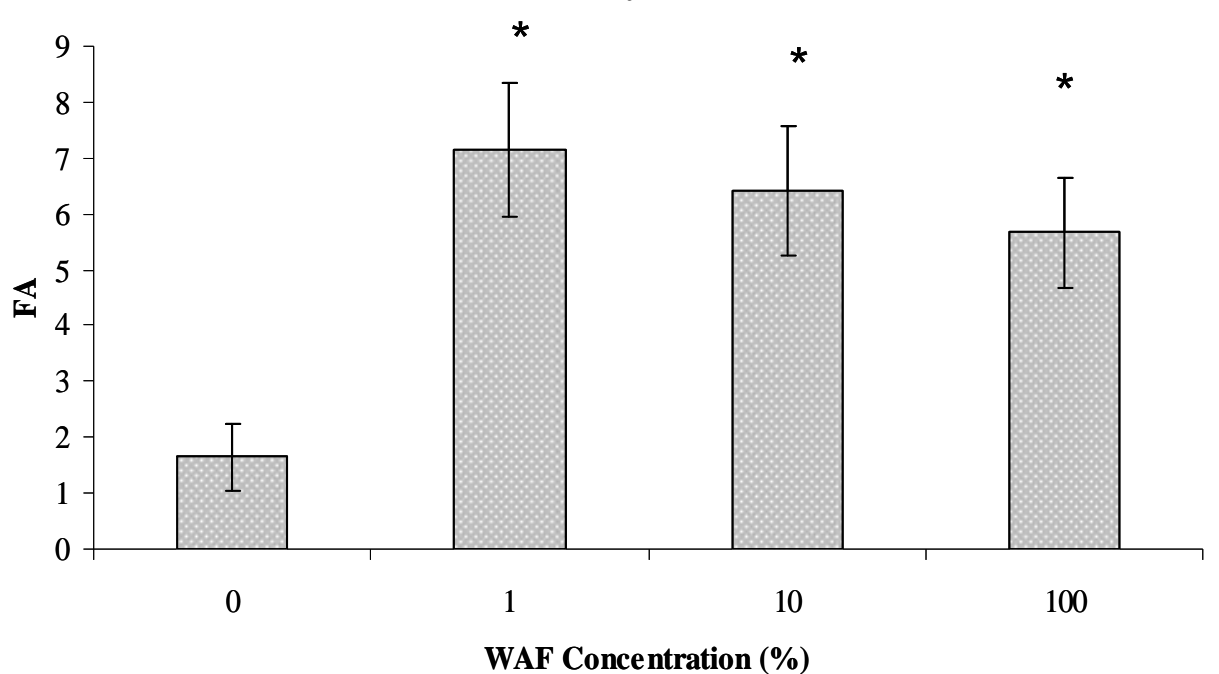

